\author{
Marianne Beaulieu* \\ Department de Medecine sociale et Preventive, Universite de \\ Montreal, Montreal, H2V 4P3, Canada \\ Dates: Received: 20 April, 2015; Accepted: 13 \\ February, 2016; Published: 15 February, 2016 \\ *Corresponding author: Marianne Beaulieu, \\ Department de Medecine sociale et Preventive, \\ Universite de Montreal, Montreal, H2V 4P3, Canada, \\ E-mail: beaulieu.marianne@gmail.com \\ www.peertechz.com \\ ISSN: 2455-3786
}

Keywords: HIV; AIDS; Women; community-based research; participatory research; minority; African; Carribean; Black
Opinion

\section{Using Participatory Research to Work With Women from Ethnic Minorities at Risk for HIV Living In Industrialized Countries}

\section{Opinion}

In Canada, people from countries where HIV is endemic are still over-represented in the epidemic [1]. Heterosexual transmission accounted for $13.9 \%$ of new infections in 2014, whereas people born in HIV-endemic countries represented approximately $2.5 \%$ of the overall Canadian population [1]. HIV has struck a disproportionate number of women, accounting for most of annually reported HIV cases [2]. Thus, a substantial portion of women living with HIV in Canada belong to African, Caribbean, and Black communities (WACB) [3]. At this point, consistent and correct use of the male condom is the most widely accepted method to prevent HIV transmission among sexually active individuals. However, compared to their Caucasian counterparts, WACB do not consistently use condoms [4-10], as they tend to have difficulty negotiating its use [10-12]. The growing number of cases in these populations suggests that current preventive interventions involving condom promotion are insufficient [13].

Approaches designed exclusively by researchers to lower vulnerability to HIV in WACB have generally been based on behavioral change theories (BCT), which suggest that vulnerability is a consequence of individual lifestyle, and hence individuals' risk behaviors [14].

However, the literature suggests that inconsistent condom use should be analyzed taking into account the social context that produces it. Particularly for WACB, sexual behaviors are part of the power imbalance that socializes them to be sexually passive and to submit to their partner [15], greatly limiting their power to negotiate condom use. The vulnerability of WACB to HIV would therefore be attributed less to lack of skills, but more to a lack of power in their relationships with men $[11,16]$. Interventions targeting these women should therefore aim to empower them in their relationships [17-20]. As participatory approaches (PA) are a way to increase empowerment
[21] in oppressed people [22], they offer a promising alternative to prevent HIV infection in WACB.

This paper demonstrates the utility of PA for working with WACB at risk for contracting HIV. First, vulnerability to HIV in this population is discussed. An overview of the limitations of the most widely used individual intervention approaches is then presented, as well as a key shortcoming, namely failure to consider the social contexts that limit women's power to negotiate sexual practices. Finally, PA are presented as a promising alternative.

\section{Vulnerability of WACB to HIV}

Women's vulnerability to HIV was long blamed on sexual risk behaviors and inconsistent condom use. Traditionally, BCT have assumed that the vulnerability to HIV of WACB was caused by condom use errors and problems: a lack of skills, negative attitudes and norms, a lack of perceived control over sexual practices and because they did not feel vulnerable to HIV or did not believe in the condom's effectiveness to reduce the risk [23-31]. In short, BCT conceptualize risk behaviors as an individual's deliberate choice, yet fail to consider relational, social, and cultural aspects of sexual risk behaviors.

However, it has been recently recognized that such behaviors are deeply entwined with the social and cultural contexts that produce them. This section presents four types of vulnerability to HIV in WACB: risk behaviors, social conditions, economic dependence, and men's sexual control over women.

\section{Social conditions}

"HIV [is] driven by gender inequalities and harmful gender norms that promote unsafe sex and reduce access to HIV and sexual and reproductive health services for [women]" [32]. For WACB, social networks set particularly stringent norms. For example, according to 
the sexual double standard, men are praised for their sexual activity while women are denigrated for similar behaviors [33,34]. These norms discourage women from talking about sexuality [35-37] and this ignorance tends to give men greater control over sexual matters, creating a socially sanctioned inequality between sexual partners [15]. This power imbalance socializes women to be sexually passive and to submit to their sexual partner [15].

Consequently, gender- and power-related social and cultural norms hinder the use of preventive behaviors in WACB by restricting their potential to negotiate condom use with their male partner [38]. These norms while not completely internalized $[39,40]$, still restrict vulnerable women's behaviors and profoundly influence their sexual risk behaviors resulting in higher exposure to HIV [41]. These norms profoundly influence sexual risk behaviors among vulnerable women, with consequent higher exposure to HIV [39]. Although these norms are not completely internalized $[40,41]$, they greatly restrict women's behaviors.

This power imbalance is an important factor in the vulnerability to HIV in WACB and is often extended to the economic domain, thereby aggravating the risks of contracting HIV.

\section{Economic dependence}

The epidemic imposes a particular burden on women and girls. Economic inequality and poverty are particularly severe among women, increasing their vulnerability to HIV [18,35,38,42-45]. "In addition to their greater physiological susceptibility to HIV acquisition, the pervasive social, legal and economic disadvantages faced by women reduce their ability to protect themselves from HIV infection, and diminish access to essential HIV and reproductive health services, in particular for women living with HIV" [32].

Women generally have less education and fewer professional qualifications than men [35]. As this gives them fewer opportunities to find a well-paid job, they often remain at home taking care of children. As this is unpaid work, women often have no source of income, which places them in a precarious situation [37,39]. For poor women, the immediate survival needs (e.g., food and shelter) frequently overshadow issues of HIV and its consequences [38,44]. In order to provide for their basic needs, many women are forced to depend on men for money $[20,39,46,47]$ and refusing to have unsafe sex may have serious consequences for their financial security and family living conditions (e.g., losing their home) [41]. The greater their economic dependence, the greater the likelihood that women will engage in HIV risk behaviors [39]. Furthermore, the lack of financial resources induces some women to take up prostitution in order to meet their own and their children's needs [35,48,49], thereby putting themselves at greater risk for HIV. Still others, including many WACB, must send money to their families in their home country, which takes a heavy toll on their meager incomes [35].

Thus, a lack of financial autonomy increases the vulnerability of these women to abuse by their partner [12,16,19,42,50-52], such that men decide whether or not to use a condom. In this way, genderrelated norms combine with the social and economic dependence of women to prevent them from negotiating safe sex [53].

\section{Men's control over women}

Although women acknowledge that the risk of HIV infection is real, many are more concerned about losing their partner through insisting on condom use $[12,50,54]$. Some women are reluctant to insist on using a condom for fear that their partner will get angry [55] or will interpret this insistence as an accusation of infidelity [12]. As a result, these women avoid the negotiation to prevent conflicts that threaten the future of their relationship [56]. Thus, lack of control in the sexual domain appears to be a key determinant in condom use, and hence in exposure to HIV infection $[6,57]$.

The power imbalance between men and women may manifest as various forms of violence. Psychological, sexual, and physical violence are important risk factors for HIV [8,19,58-61], through three main mechanisms [62]: (1) by forced or coercive sexual relations with an infected partner [58]; (2) by limiting the woman's ability to negotiate safe sex [61]; and (3) by establishing a "pattern" of sexual risk-taking in individuals who have been abused in childhood or adolescence [35,39,63-66].

\section{Limitations of individual approaches to HIV prevention}

As shown above, individual approaches to prevent HIV in WACB are generally based on BCT $[56,67]$ which assume that vulnerability to HIV stems from a lifestyle that includes individual sexual risk behaviors with little influence from the social environment [68]. However, an extensive meta-analysis concludes that individual interventions designed to change behaviors in adult heterosexual populations have limited impact [56]. There are three main reasons for this.

First, interventions designed by researchers to prevent HIV using this approach aim to change the proximate determinants of risk behaviors [69]. This type of intervention is based on the traditional biomedical approach in the sense that it "treats" individuals for a specific problem [70]. Generally, the objectives of such interventions reflect the theoretical concerns of researchers who are estranged from the targeted communities, and are not meant promote empowerment or capacity building [69]. Given women's lack of power, we argue that "capacity building" is much preferable to "skills development" as a target for preventive intervention, because it implies a permanent process by which individuals and communities increase their ability to carry out basic functions, resolve problems, set and achieve goals, and understand their needs for self-development and satisfaction [71].

Second, preventive interventions designed to change sexual risk behaviors could accentuate the inequalities associated with HIV. Because these interventions assume that individuals act rationally and out of free will [72], they do not consider that vulnerable women (having less power) are less likely to adapt to new situations and therefore to benefit from this type of intervention [70,73]. In fact, because the capacity of individuals to change their behavior is closely entwined with the power imbalance in their relationship and their social situation, this capacity is likely to be limited by a lack of autonomy and power. This aspect is not considered in individual approaches [56,72]. 
Third, cultural and social dimensions appear to be central factors in HIV risk behaviors in WACB, because they exert a profound influence on women's capacities to negotiate condom use. This limits the effectiveness of individual approaches to HIV prevention, because they do not account for the social nature of HIV risk behaviors [72]. Therefore, it appears that effective interventions would aim to influence community norms and establish strategies to reduce risks at multiple levels: interpersonal, local, community, and cultural [67]. PA offer a step in this direction, since such approaches address problems beyond the individual level.

\section{Alternative approaches: PA to prevent HIV}

PA offer a promising alternative for HIV prevention programs targeting WACB because their primary goal is to increase the empowerment of individuals and communities [21,74], thereby restoring the power balance.

More than a rigid research methodology, PA constitute a social process that aims to restore power to those who are oppressed [22]. These approaches are based on both local knowledge and experience [75] and professional practices [76]. The use of local knowledge and experience encourages these communities to take concrete action to improve their lives [77], whereas input from professionals supports the design of formal interventions to resolve problems $[74,78]$.

Through this participatory process, power is shared more equitably between researchers and participants, resulting in a collaboration between equal partners [21,78] having different, but nonetheless relevant, expertise. This collaboration requires a mutual sharing of knowledge and learning [76]. The PA requires the community to be engaged throughout the duration of the project [21], so that the key goals of empowerment and capacity building can be achieved.

However, some challenges in developing PA have been documented [79]. First, there is no set of PA principles applicable to all research projects. Each participatory process has to be defined. Therefore, multiple research designs and methodologies are available, "each partnership has to decide what works best for its research question or intervention goal in its particular community context" [79]. Each project is thus extremely time-consuming and involves negotiating throughout the process. Moreover, given the uniqueness of each project, it is impossible to accurately predict future outcomes. Second, it is difficult to define the "community". However, this definition is crucial considering that it is used to target partners and community representatives involved from the project design. They will be in a position of power to influence the whole project and work for the recognition of the community priorities.

\section{The advantage of PA to prevent HIV: empowerment}

Despite these limitations, we suggest PA can contribute to HIV prevention. Instead of attempting to change individual behaviors in isolation from their social circumstances, HIV preventive interventions in WACB should help them restore the power balance in their relationships and foster empowerment [15,17-20] in order to reduce their dependence on men. Engaging communities through empowerment is one way to deal with the power issues $[19,20,80]$ that render WACB vulnerable.
Empowerment is defined as "a participatory process of learning to critique and transform individual feelings, thoughts, and actions, as well as the organization of society, so that power and resources can be shared equitably" [81]. Thus, an intervention that proposes community empowerment generally attempts to achieve changes at the community level by engaging the community to define its own health issues, identify these determinants, and take individual and collective actions to modify those determinants [69]. According to this definition, empowerment can be applied to different areas (sexual negotiation, financial autonomy) and analyzed or practiced at different levels (e.g., individuals, couples, groups, organizations) [69].

In a PA, it is assumed that the community's empowerment would be increased by 1) recognition of the legitimacy of local knowledge, experience, and capacities, 2) community control over the project, and 3 ) the community's active participation throughout project duration $[21,78]$. This approach is based on the premise that participation by community members will encourage them to "own" local problems so that they can foster local solutions [78]. For HIV prevention, empowerment may take the form of economic opportunities to reduce women's dependence, preventive measures that remain under women's control, and political and social progress to give women a voice [82].

By fostering community empowerment, PA encourages individuals and communities to assume power. For individuals, these approaches aim to develop community and healthy capacities such as group decision making and awareness of available resources. For communities, PA aim to create new networks, resources, and opportunities designed to reduce HIV risks [69]. In this way, women's empowerment promotes a sense of having the capacity and power to fight the social battles that could lead to greater autonomy. Thus, empowerment addresses women's lack of power in their relationships.

Programs that target women's empowerment aim to improve their access to information, services, and technologies, but they also go further by creating a group identity that becomes a source of power, by encouraging women to take part in decision making [37] and by providing women with the opportunities to play a more active role in defining sexual relations and gender roles [83]. Only then can a profound change in gender relations take place, and only in this way can women gain greater control over their physical, economic, and social lives.

\section{Conclusion}

For many years, the HIV epidemic has been recognized as a major public health issue around the world. In North America, this epidemic is wielding a disproportionate impact on WACB from countries where HIV is endemic, and the majority of women living with HIV have been infected through heterosexual contact. It is therefore important to develop interventions to help these women reduce their risk of contracting HIV.

In light of recent research, it appears that individual approaches designed by researchers to changing HIV risk behaviors in WACB are ineffective and do not reduce their vulnerability. Their effectiveness is limited because they do not address the main vulnerabilities, which 
ensue from social conditions, lack of power in relations with men, and economic dependence.

Therefore, participatory approaches offer a promising alternative for working with WACB at risk for HIV, as the primary objective of these approaches is to increase the empowerment of communities and participants and thereby restore the power balance at several levels. This type of approach has been proven relevant and effective in increasing the empowerment of vulnerable populations, and consequently changing the social conditions that lead to HIV exposure. They merit consideration for use in HIV prevention strategies targeting populations that are vulnerable due to lack of social and relational power, such as WACB.

\section{Funding}

This work was supported by the Canadian Institutes for Health Research (CIHR) Community-Based Research Program (Doctoral Research) and the Strategic Training Program in public and population health research of Quebec (a partnership of the Institute of Population and Public Health and the Institute of Health Services and Policy Research of the CIHR and the Quebec Population Health Research Network). The author also wants to acknowledge financial support from the Institute of Public Health Research of the University of Montreal, the Chair on Community Approaches and Health Inequalities (funded by the Canadian Health Services Research Foundation and the Canadian Institute of Health Research), and the CIHR Social Research Centre in HIV Prevention, the Centre de recherche Hopital Charles-Lemoyne, and the TD Canada Trust.

\section{Acknowledgments}

The author wish to thank Louise Potvin, Stephanie Alexander, Daniel Fuller, Geneviève Mercille and Martine Shareck for their useful comments.

\section{References}

1. Public Health Agency of Canada (2015) Summary Estimates of HIV incidence, prevalence and proportion undiagnosed in Canada, 2014. Ottawa: Public Health Agency of Canada.

2. Agence de la santé publique du Canada (2012) Actualités en épidémiologie du VIH/sida: Le VIH/sida au Canada chez les personnes originaires de pays où le VIH est endémique. Ottawa: Agence de la santé publique du Canada.

3. Espinoza L, Hall HI, Hardnett F, Selik RM, Ling Q, et al. (2004) Characteristics of persons with heterosexually acquired HIV infection, United States 19992004. Am J Public Health 97: 144-149.

4. Geringer WM, Marks S, Allen WJ (1993) Knowledge, attitudes, and behavior related to condom use and STDs in a high risk population. J Sex Res 30: 7583.

5. Moreno CL, El-Bassel N, Morrill AC (2007) Heterosexual women of color and HIV risk: Sexual risk factors for HIV among Latina and African American women. Women Health 45: 1-15.

6. Pulerwitz J, Amaro H, De Jong W, Gortmaker SL, Rudd R (2002) Relationship power, condom use and HIV risk among women in the USA. AIDS Care 14: 789-800.

7. St Lawrence JS, Eldridge GD, Reitman D, Little CE, Shelby MC, et al (1998) Factors influencing condom use among African American women: Implications for risk reduction interventions. Am J Community Psychol 26: 7-28.
8. Teitelman AM, Ratcliffe SJ, Morales-Aleman MM, Sullivan CM (2008) Sexual relationship power, intimate partner violence, and condom use among minority urban girls. J Interpers Violence 23: 1694-1712.

9. Wingood GM, DiClemente RJ (1998) Gender-related correlates and predictors of consistent condom use among young adult African-American women: A prospective analysis. Int J STD AIDS 9: 139-145

10. Wingood GM, DiClemente RJ (1998) Partner influences and gender related factors associated with non-condom use among young African American women. Am J Community Psychol 26: 29-51.

11. Catania JA, Coates TJ, Kegeles S, Fullilove MT, Peterson J, et al. (1992) Condom use in multi-ethnic neighborhoods of San Francisco: The population-based AMEN (AIDS in Multi-Ethnic Neighborhoods) study. Am J Public Health 82: 284-287.

12. Fullilove MT, Fullilove RE, Haynes K (1990) Black women and AIDS prevention: A view towards understanding the gender rules. J Sex Res 27: 47-64.

13. Moreno R, Nababan HY, Ota E, Wariki WM, Ezoe S, et al. (2014) Structural and community-level interventions for increasing condom use to prevent the transmission of HIV and other sexually transmitted infections. Cochrane Database Syst Rev 7: CD003363.

14. Lalonde M (2014) A new perspective on the health of Canadians. Working paper. Ottawa: Information Canada.

15. Amaro H (1995) Love, sex, and power: considering women's realities in HIV prevention. Am Psychol 50: 437-447.

16. Gómez CA, Marin BV (1996) Gender, culture, and power: Barriers to HIVprevention strategies for women. J Sex Res 33: 355-362.

17. Kapileni E (2000) Health and disease in southern Africa: A comparative and vulnerability perspective. Soc Sci Med 50: 965-983.

18. Land H (1994) AIDS and women of color. Families in Society 75: 355-361.

19. Sa Z, Larsen U (2008) Gender inequality increases women's risk of HIV infection in Moshi, Tanzania. Journal of Biosocial Science 40: 505-525.

20. Williams CC, Newman PA, Sakamoto I, Massaquoi NA (2009) HIV prevention risks for Black women in Canada. Soc Sci Med 68: 12-20.

21. Mason R, Boutilier M (1996) The challenge of genuine power sharing in participatory research: The gap between theory and practice. Can J Commun Ment Health 15: 145-152.

22. Hall BL (1992) From margins to center? The development and purpose of participatory research. Am Sociol 23: 15-28.

23. Bandura A (1977) Social learning theory. Englewood Cliffs: Prentice Hall.

24. Bowleg L, Belgrave FZ, Reisen CA (2000) Gender roles, power strategies, and precautionary sexual self-efficacy: Implications for black and Latina women's HIVIAIDS protective behaviors. Sex Roles 42: 613-635.

25. Lauby JL, Semaan S, O'Connell A, Person B, Vogel A (2001) Factors related to self-efficacy for use of condoms and birth control among women at risk for HIV infection. Women Health 34: 71-91.

26. Raiford JL, Wingood GM, Diclemente RJ (2007) Correlates of consistent condom use among HIV positive African American women. Women Health 46: 41-58.

27. Ajzen I, Fishbein M (1980) Understanding attitudes and predicting social behavior. Englewood Cliffs: Prentice-Hall.

28. Ajzen I (1991) The theory of planned behavior. Org Behav Hum Decis Process 50: 179-211.

29. Salabarría-Peña Y, Lee JW, Montgomery SB, Hopp HW, Muralles AA (2003) Determinants of female and male condom use among immigrant women of Central American descent. AIDS Behav 7: 163-174.

30. Rosenstock IM, Strecher VJ, Becker MH (1994) The health belief model and 
HIV risk behavior change. In: DiClemente RJ, Peterson JL, eds. Preventing AIDS: Theories and methods of behavioral interventions. New York: Plenum 5-24.

31. Sanders SA, Yarber WL, Kaufman EL, Crosby RA, Graham CA, et al. (2012) Condom use errors and problems: a global view. Sex Health 9: 81-95

32. UNAIDS (2013) Global Report on the global AIDS epidemic. Switzerland UNAIDS.

33. Fasula AM, Miller KS, Wiener J (2007) The Sexual Double Standard in African American Adolescent Women's Sexual Risk Reduction Socialization. Women \& Health 46: 3-21.

34. Kreager DA, Staff J (2009) The sexual double standard and adolescent pee acceptance. Soc Psychol Q 72: 143-164.

35. Moreno CL (2007) The relationship between culture, gender, structura factors, abuse, trauma, and HIVIAIDS for Latinas. Qual Health Res 17: 340352

36. Zambrana RE, Cornelius LJ, Boykin SS, Lopez DS (2004) Latinas and HIV/ AIDS risk factors: Implications of harm reduction strategies. Am J Public Health 94: 1152-1158.

37. Gupta GR (2000) Gender, sexuality, and HIVIAIDS: The what, the why, and the how. Can HIV AIDS Policy Law Rev 5: 86-93.

38. Scott KD, Gilliam A, Braxton K (2005) Culturally competent HIV prevention strategies for women of color in the United States. Health Care Women Int 26: 17-45.

39. Bontempi JB, Eng E, Quinn SC (2008) Our men are grinding out: A qualitative examination of sex ratio imbalances, relationship power, and low-income African American women's health. Women Health 48: 63-81.

40. Susser I, Stein Z (2000) Culture, sexuality, and women's agency in the prevention of HIVIAIDS in Southern Africa. Am J Public Health 90: 10421048.

41. Wingood GM, DiClemente RJ (2000) Application of the theory of gender and power to examine HIV-related exposures, risk factors, and effective interventions for women. Health Educ Behav 27: 539-565.

42. Adimora AA, Schoenbach VJ, Martinson FE (2001) Social context of sexua relationships among rural African Americans. Sex Transm Dis 28: 69-76.

43. Centers for Disease Control and Prevention (CDC) (2005) HIV transmission among Black women-North Carolina. MMWR Morb Mortal Wkly Rep 54: 8994.

44. Mays VM, Cochran SD (1988) Issues in the perception of AIDS risk and risk reduction activities by Black and Hispanic/Latina women. Am Psychol 43: 949-957.

45. McNair LD, Prather CM (2004) African American women and AIDS: Factors influencing risk and reaction to HIV disease. J Black Psychol 30: 106-123.

46. Bruhier MA, Drover G (2005) Income of Black women in Canada. Canadian Association of Social Workers.

47. Foster N (2007) Reinscribing Black women's position within HIV and AIDS discourses. Feminism \& Psychology 17: 323-329.

48. Evans C, Lambert $H$ (2008) The limits of behaviour change theory: Condom use and contexts of HIV risk in the Kolkata sex industry. Cult, Health \& Sex 10: $27-42$.

49. Chathukulam J, John MS (2002) The primacy of gender in STD and HIV prevention programmes: The case of female sex workers of Kottayam, Kerala. Indian Journal of Gender Studies 9: 183-202.

50. Crosby RA, DiClemente RJ, Wingood GM, Salazar LF, Head S, et al. (2008) Sexual agency versus relational factors: a study of condom use antecedents among high-risk young African American women. Sex Health 5: 41-47.

51. Wingood GM, Hunter-Gamble D, DiClemente RJ (1993) A pilot study of sexual communication and negotiation among young African American women: Implications for HIV prevention. J Black Psychol 19: 190-203.

52. Jewkes RK, Levin BL, Penn-Kekana LA (2003) Gender inequalities, intimate partner violence and HIV prevention practices: findings of a South African cross-sectional study. Soc Sci Med 56: 125-134.

53. Gupta GR, Weiss E (1993) Women and AIDS: Developing a new health strategy. Washington, DC: International Center for Research on Women (ICRW).

54. Jones R (2006) Scripts and power: A framework to explain urban women's HIV sexual risk with male partners. Nurs Clin N Am 41: 425-436.

55. Pulerwitz J, Gortmaker SL, DeJong W (2000) Measuring sexual relationship power in HIVISTD research. Sex Roles 42: 637-660.

56. Logan TK, Cole J, Leukefeld C (2002) Women, sex, and HIV: Social and contextual factors, meta-analysis of published interventions, and implications for practice and research. Psychol Bull 128: 851-885.

57. Harvey SM, Bird ST, Galavotti C, Duncan EA, Greenberg D (2002) Relationship power, sexual decision making and condom use among women at risk for HIVISTDs. Women Health 36: 69-84.

58. Dunkle KL, Jewkes RK, Brown HC, Gray GE, Mclntryre JA, et al. (2004) Gender-based violence, relationship power, and risk of HIV infection in women attending antenatal clinics in South Africa. Lancet 363: 1415-1421.

59. Krishnan S, Dunbar MS, Minnis AM, Medlin CA, Gerdts CE, et al. (2008) Poverty, gender inequities, and women's risk of human immunodeficiency virus/AIDS. Ann N Y Acad Sci 1136: 101-110.

60. Maman S, Mbwambo JK, Hogan NM, Kilonzo GP, Campbell JC, et al. (2002) HIV-positive women report more lifetime partner violence: findings from a voluntary counseling and testing clinic in Dar es Salaam, Tanzania. Am J Public Health 92: 1331-1337.

61. Wingood GM, DiClemente RJ (1997) The effects of an abusive primary partner on the condom use and sexual negotiation practices of AfricanAmerican women. Am J Public Health 87: 1016-1018.

62. Maman S, Campbell J, Sweat MD, Gielen AC (2000) The interactions of HIV and violence: directions for future research and interventions. Soc Sci Med 50: 459-478.

63. Arriola KR, Louden T, Doldren MA, Fortenberry RM (2005) A meta-analysis of the relationship of child sexual abuse to HIV risk behavior among women. Child Abuse \& Negl 29: 725-746.

64. Cohen M, Deamant C, Barkan S, Richardson J, Young M, et al. (2000) Domestic violence and childhood sexual abuse in HIV-infected women and women at risk for HIV. Am J Public Health 90: 560-565.

65. Miller M (1999) A model to explain the relationship between sexual abuse and HIV risk among women. AIDS Care 11: 3-20.

66. Zierler S, Feingold L, Laufer D, Velentgas P, Kantrowitz-Gordon I, et al. (1991) Adult survivors of childhood sexual abuse and subsequent risk of HIV infection. Am J Public Health 81: 572-575.

67. Aggleton P, O'Reilly K, Slutkin G, Davies P (1994) Risking everything. Risk behavior, behavior change and AIDS. Science 265: 341-345.

68. Bajos N, Marquet J (2000) Research on HIV sexual risk: Social relationsbased approach in a cross-cultural perspective. Soc Sci Med 50: 1533-1546.

69. Beeker C, Guenther-Grey C, Raj A (1998) Community empowerment paradigm drift and the primary prevention of HIVIAIDS. Soc Sci Med 46: 831842.

70. Cohen DA, Scribner R (2000) An STD-HIV prevention intervention framework Aids Patient Care STDs 14: 37-45.

71. Horton D, Alexaki A, Bennett-Lartey S (2003) Evaluating Capacity Development: Experiences from Research and Development Organizations around the World. Ottawa: International Service for National Agricultural Research (ISNAR)/International Development Research Centre (IDRC).

72. Fisher J, Fisher W (2000) Theoretical approaches to individual-level change 
in HIV risk behavior. In: Peterson J, DiClemente RJ, eds. Handbook of HIV prevention. New York: Kluwer Academic/ Plenum 3-56.

73. Frohlich KL, Potvin L (2008) Transcending the known in public health practice: the inequality paradox: the population approach and vulnerable populations. Am J Public Health 98: 216-221.

74. Green LW, George MA, Frankish DM, Herbert CJ, Bowie WR, et al (1995) Study of Participatory Research in Health Promotion: Review and Recommendations for the Development of Participatory Research in Health Promotion in Canada, Ottawa: The Royal Society of Canada.

75. Chesler MA (1999) Participatory action research with selfhelp groups: An alternative paradigm for inquiry and action. Am J Community Psychol 19: 757-768.

76. Macaulay AC, Cargo M, Bisset S, Delormier T, Lévesque L, et al. (2006) Community empowerment for the primary prevention of type 2 diabetes: Kanien'keha: ka (Mohawk) ways for the Kahnawake Schools Diabetes Prevention Project. In: Ferreira ML, Lang GC, eds. Indigenous Peoples and Diabetes: Community Empowerment and Wellness. Durham, NC: Carolina Academic Press 407-458.

77. Etowa JB, Bernard WT, Oyinsan B, Clow B (2007) Participatory action research (PAR): An approach for improving Black women's health in rural and remote communities. J Transcult Nurs 18: 349-357.

78. Rains JW, Ray DW (1995) Participatory action research for community health promotion. Public Health Nurs 12: 256-261.

79. Israel BA, Schulz AJ, Parker EA, Becker AB, Allen AJ, et al. (2011) Critical issues in developing and following CBPR principles. In: Minkler M, Wallerstein $\mathrm{N}$, eds. Community-based participatory research for health: From process to outcomes. San Francisco, CA: Jossey-Bass 47-66

80. Gutierrez L, Oh HJ, Gillmore MR (2000) Toward an understanding of (em) power (ment) for HIVIAIDS prevention with adolescent women. Sex Roles 42: 581-611.

81. Townsend E (1998) Good intentions overruled: A critique of empowerment in the routine organization of mental health services.Toronto, On: University of Toronto Press.

82. Romero L, Wallerstein N, Lucero J, Fredine HG, Keefe J, et al. (2006) Woman to woman: Coming together for positive change-using empowerment \& popular education to prevent HIV in women. AIDS Educ Prev 18: 390-405.

83. Pomeroy C (2008) Social Determinants of HIV Risk in Women. Virtual Mentor 10: $457-464$

Copyright: (C) 2016 Beaulieu M. This is an open-access article distributed under the terms of the Creative Commons Attribution License, which permits unrestricted use, distribution, and reproduction in any medium, provided the original author and source are credited. 